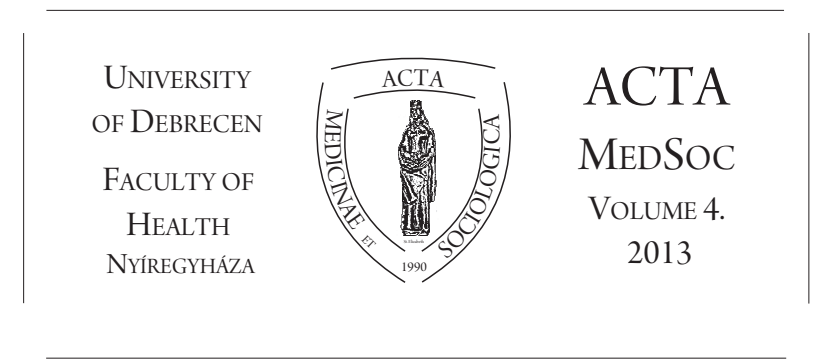

\title{
Social economy and social work in Europe
}

\section{Christine Gruber}

FH-Campus Wien, Ausztria

DOI: $10.19055 / \mathrm{ams} .2013 .4 / 8-9 / 3$

The following article's first part focuses on social work and social economy as well as the relation between the two. Especially, the differences in understanding and the grade of recognition of social economy in the European countries will be addressed. Subsequently, part two contains an analysis of three specifics of social economy - the different functions of social economy organizations, the creation of a quasi-market and quality assessment. Finally, the effects managerialism has on organizations in the social sector as well as future perspectives are illustrated.

The present article is divided into the following parts:

1. Introductory observations

2. Concepts of social work and social economy and the relation between the two

3. Specific characteristics of social economy

4. Effects

5. Summary and outlook

\section{Introductory observations}

In the German-speaking world, the analysis of social work and social economy and the relation between the two needs to take place before the background of the changes in the welfare-state discussion that have occurred during the past two decades (cf. Gruber 2008, S. 53). The latter is strongly influenced by the increasingly 
emphasized empty state finances, the economical use of public resources and the questioning of the state's role with regards to the social sector.

In summary, the following trends are visible in the 21st century:

- Legitimization of organizations in the social sector concerning their financiers with regards to the utilization of financial means is necessary. (What is done, how it is done and how much it costs must be disclosed.)

- Organizations act in accordance with business principles and the public administration in its role as important investor and provider of social services follows the New Public Management Concept.

- Efficiency and effectiveness need to be verified.

- Free-market elements as well as competitive elements have spread throughout the social sector.

- Benchmarks between organizations have become reality.

- Privatization of services as a result of the outsourcing of social services that used to be provided by the state.

- Financing is based on service agreements with non-governmental organizations.

- Alternative procurement of resources through monetary donations and donations in kind as well as volunteering activities become increasingly necessary for running projects

This clearly shows how the parameters of the provision of social work have changed in the past decades and how economic thinking has entered the realm of social work. The changes in policy, society and legal environments have had a decisive effect on the conditions for the organizations in the social sector which will be discussed in further detail later, before that, however, the understanding of social work and social economy as well as the relation between the two shall be analysed.

\section{Regarding the concept of social work, social services and social economy and the relation between the two}

\section{Social work}

Social work is tightly connected with the principle of social security in a welfare state. Based on this public contract, social work becomes active when (individual) problem solving abilities do not suffice and a solution would be to the benefit of socio-political interests. This societal contract also implies that social work is 
mostly financed publicly. Social work fulfils an important integrative function for society.

Social workers do their work with many different groups of society, families, children and teenagers amongst others, especially when the child's welfare is in danger. They work with people who are threatened by poverty, unemployment, who might lose or have lost their homes, people who are delinquent or victims of crimes. They also work with sick, disabled and elderly people who do not only require physical aid but psychosocial support as well.

Social workers' interventions can take place in (sometimes overlapping) social environments (districts, regions). Social workers stand for structural changes to resolve social problems. The society's development changes the requirements for social work.

From an economic perspective, social work can be considered a social service and it thus constitutes one of many services provided by social economy.

\section{Social services}

Social services are aimed at (disadvantaged) persons or groups in society (target group) and they serve to improve the persons' situation in life (target). They comprise counselling-, treatment-, support- and care-services as well as activation-, occupation- and qualification-services, as socially supportive aspects play a decisive role.

The rendering of social services is characterized by the following particularities:

- Social services are not concrete (intangibility)

- Social services cannot be stored; they are consumed immediately and production and consumption happen simultaneously

- When rendering social services, the cooperation of the recipient is usually necessary.

- The result of social services often constitutes a change in behaviour which means that the result can hardly be measured.

Social services can be rendered by numerous groups of actors; the professional and organized offer is made by social economy.

\section{Social economy}

Social economy can be regarded in various aspects and as part of various disciplines. Depending on the discipline, different points of view move into the centre. The present article deals with the term from an economic and primarily business-oriented point of view. 
According to the (business-) economic approach, a social economy organization is one that provides professional social services commercially thus making them valuable in money terms. Social economy organizations serve a social and an economic purpose, the purpose of achieving individual and collective welfare. Social economy thus is the entirety of social economy organizations. In order to be able to define social economy, the social purpose of activities and operations that are associated with this area, are decisive. Social economy organizations/enterprises/companies differ in legal forms (association, foundation, non-profit limited liability company) and sizes.

Within the framework of the present analysis the term social economy is limited to social service enterprises, hence self-help groups and/or active citizenship (active civil society) are not taken into account. Due to financial limitations, parts of the services can sometimes only be provided in connection with voluntary work though.

A further reason for said constriction is deducted from the concept of economy. Since goods/resources are scarce, the economic principle ('rational principle') with the 2 alternatives

1. Reaching a goal using minimal resources or

2. Reaching the best possible goal using the available resources (principle of maximum return and minimum effort),

is applied.

\section{Sectorial anchoring of social economy}

Organizations' economic activity can basically be divided into three different sectors:

- market sector/profit sector

- public sector/public administration

- non-profit sector

\begin{tabular}{|c|c|c|}
\hline $\begin{array}{c}\text { profit-sector } \\
\text { private sector }\end{array}$ & $\begin{array}{c}\text { non-profit sector } \\
\text { (third sector) }\end{array}$ & $\begin{array}{c}\text { public sector } \\
\text { administration }\end{array}$ \\
\hline
\end{tabular}

Depending on how social economy is defined, it is interpreted and located differently.

The German-speaking discussion often summarizes social services provided by all three sectors within the term of social economy, hence the carriers of free welfare work as well as public and commercial providers of social services are comprised under one term.

If social economy was only viewed as a part of the non-profit sector however, public and private-sector offers within the framework of welfare production would not be taken into account. Social economy and the non-profit sector are not seen as equal in this article because the latter also comprises the areas health, culture 
and education as well as active citizenship. The non-profit sector is often called third sector (after state and market), too. However, a more detailed discussion of the concept is not part of the present article.

There are parallels and differences between the (social economy) organizations in the three sectors. As opposed to profit-organizations from other economic sectors, questions regarding the measuring of performance and success as well the external relationship with clients and stakeholders in social economy have to be designed differently. In social sector organizations, business efficiency always has to be evaluated taking into account effectiveness. On the one hand, in the area of individual social economic enterprises, the WHAT, i.e. the content of the service, the professional side, has to be taken into account. On the other hand though, it's also about the HOW, i.e. in how far the service can be rendered - from a business point of view - as financially sound as possible.

Since there are more profit-oriented enterprises in the social sector that have entered the competition by now, the arising challenges and - last but not least also the effects on the transformation of the entire sector and the range of social services must be addressed. Basically - on a macro level - politics have to clarify, what the division of labour between the state and the non-public sector should look like.

\section{Social economy as a concept in a European context}

Depending on which concept (e.g. social economy, non-profit, third sector) dominates in the individual European countries, the understanding of social economy in practice, in the administration and in science is very different.

According to the prominence of social economy, European countries can be divided into three groups:

- Countries, where the concept/understanding of social economy is widely accepted. These include France, Spain, Portugal, Italy, Belgium, Ireland and Sweden. In France and Spain social economy is legally anchored.

- Countries with medium acceptance. These include Cyprus, Denmark, Finland, Greece, Luxembourg, Latvia, Malta, Poland and Great Britain.

- Countries with low prominence and acceptance. These include Germany, Austria, Czech Republic, Hungary, Estonia, Lithuania, Slovenia, Slovakia and the Netherlands.

Legal forms and organizational forms in social economy differ within the individual countries, too. Most organizations within the EU constitute themselves as cooperatives, mutual societies, associations or foundations (Chaves/Monzon 2007, p. 5). Also the individual EU-countries have their own rules for the promotion of voluntary work. This diversity makes the design of a common European policy for social economy very difficult. 
In 1989 the term social economy - deducted from the French ,economie sociale' - became part of the European Union's official jargon. From the European Commission's viewpoint, social economy has positioned itself as a pole of public utility between the profit-oriented sector and the public sector (Chaves/Monzon 2007, p. 9 ). In order to emphasize the economic significance, a difference is made between a business-oriented and a non-market oriented part of social economy, while retaining that there is a relation between the two.

For the benefit of understanding social economy in the EU, it's crucial to keep in mind that the borders between the private market model (model of competitiveness) and the public sector have shifted ever since the introduction of the common market. Originally, the public sector was oriented towards national principles when it came to providing the citizens with social and health services. The European Commission has/had the goal to stretch the common market out into as many areas of daily life as possible which is why more and more areas were privatized and organized in a profit-oriented way. Theoretically, the social sector remains/remained part of the national competences but it was grasped by the aforementioned logic anyhow. In summary it can be said that the EU's policy connects diverse goals with social economy. These goals are to create jobs, produce social services and thus welfare and social cohesion. Furthermore, the further expansion of social economy supports the development of democracy as well as communal development (Chaves/Monzon 2007, p. 27ff).

\section{Specific characteristics of social economy organizations}

\subsection{Complex target system}

Apart from providing professional services, social economy organizations fulfil other important societal and political functions.

As shown in figure 1, social economy organizations pursue three main goals, goals which make them substantially different from organizations in other sectors:

- Service

Social economy organizations render and offer professional social services in different areas.

- Support of social cohesion

Through the range of professional services, the personal and social integrity of people is supported and thus an important contribution to societal stability, social cohesion and inclusion is made.

- Partial commitment/partiality

Social economy organizations take their clients part when dealing with public and political institutions if their clients are not capable of promoting their own interests in a sufficient way. The frequently recognize the effects of 
societal development at an early stage and initiate the necessary political discussion/opinion-making process.

\section{politics / political system \\ creation of collectively \\ binding standards}

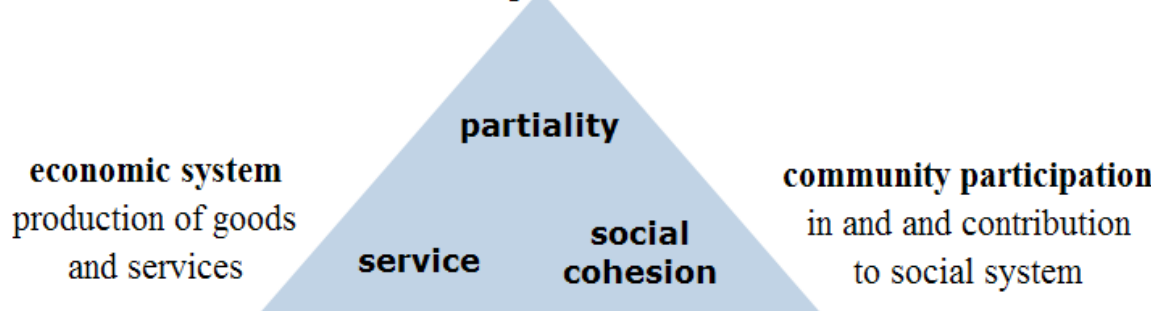

Figure 1. Targets of Social Economy.

Social economy organizations' targets sometimes have to meet more contradictory requirements than those of enterprises from other sectors. Balancing said contradictions can be very difficult. Equilibrating different systems' diverse logics and different stakeholders' expectations means that there are tough requirements the management has to meet. US-American management researcher Peter Drucker's (2001) views on non-profit organizations are that they should bring change to peoples' lives. The same goes for social economy organizations. This means that they have to do more than just sell social services.

\subsection{Market orientation ,quasi-market'}

The application of (business-based) concepts of rationality to social economy is also visible in its absorption of market orientation. In a system coined by a business approach, the 'free play of market forces' is favoured - albeit limited by governmental framework conditions. The market is where supply and demand meet, the two are equilibrated by the price.

In a social economy such an approach is not possible because we often encounter characteristics that might lead to a failing of the market.

On the demand-related side of social services, there are a few particularities. A person who is in need of a social service, often doesn't voice their demand as a homo oeconomicus because persons who require social services often only do so when they're in distress. As shown in figure 2, often it's not the consumers of social services that actually pay for them. 


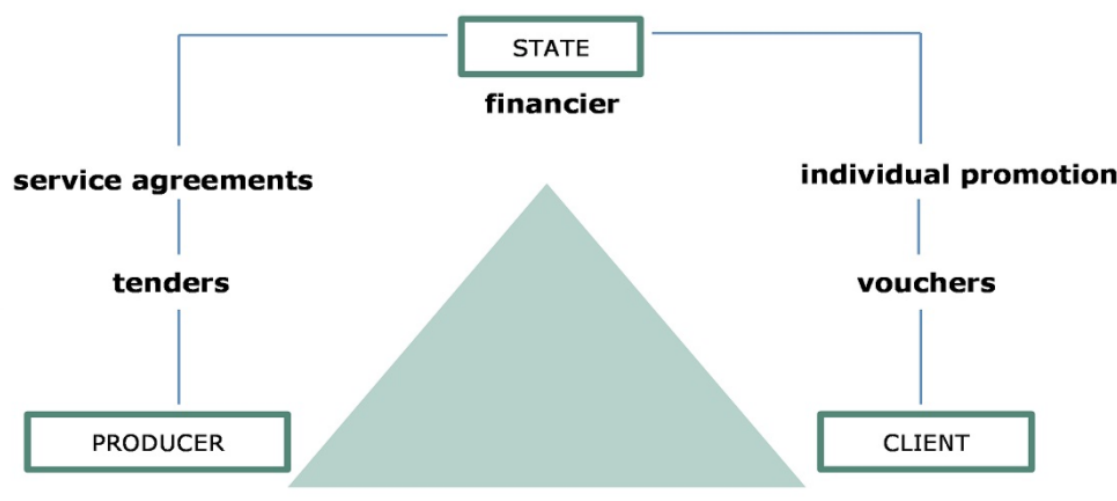

Figure 2. Social Economy and Virtual Markets.

If we talk about market solutions or competition in this context, we refer to the introduction of so-called "quasi - markets". These are politically produced market structures that are mainly publicly funded.

In such a scenario the state often enters into a special role. It functions as a regulating entity, and in this function it can represent the supplier as well as the customer.

Marketization and privatization are supposed to introduce more competition into the social sector. Hence more and more services that were formerly offered by a public entity were outsourced or privatized. In order to make this possible public authorities changed the relations between suppliers and customers of social services - sometimes massively. In cases where the public authorities finance the suppliers, this has recently led to a change in financing possibilities. A change from flat-rate subsidies to detailed accounting of services as well as tendering and award procedures took place (cf. Zauner 2006).

In order to strengthen the customers' position on the market, the government provides them with financial means or vouchers instead of non-cash benefits. The awarding of financial means is supposed to empower the consumers to appear as paying consumers on the market for social services. This is supposed to lead to more competition, lower prices, more customer orientation and higher quality services amongst the supplying organizations. The aims of all these governmental activities are lower prices and higher quality for the services on offer. As far as the effects that market orientation has on the organizations in the social sector are concerned, there has been little research so far. Further research would be needed here.

\subsection{Assessment of quality and success}

The control of price via quality is hardly possible in the sector of social economy. And, since the quality of social services is hard to assess, another crucial question 
that arises in connection with social economy is what quality actually is. When discussing quality, the following aspects need to be taken into consideration: Quality needs to be operationalized, which means that:

- quality needs to be intersubjectively communicable,

- quality needs to be deductible from aims/measures and

- in how far these targets are reached needs to become measurable and verifiable.

In order to be able to define quality (success), the formulation of targets is of the utmost importance. Now the question arises, which specific effects organizations or measures are striving to achieve. Effects can be reached on different levels (individual, organizational, societal). And, with respect to the time it takes for the effects to become visible, a distinction between short-, medium- and longterm effects can be made. The decisive quality feature in an organization/a social measure lies in its assessment, as to whether the intended effect was reached. If this is the case, a certain quality or rate of success can be ascribed to an organization. It's always of great importance, which measures (processes/output) are taken based on which resources (input) in order to reach a certain goal. Now the operative effect can be considered equal to the effectiveness, i.e. in how far a target was reached. Efficiency, however, is intended in economic terms, i.e. reaching the intended targets while using as little resources (economic principle) as possible. Efficiency rates the relation between the resources that are applied (input) and the rendered services (output/outcome). Ideally, effects are the result of the services that are rendered, thus they are their consequence.

\section{The interaction between target effects, target actions and target services}

In order to be able to conduct an assessment of a target, target effects have to be formulated clearly enough to make them assessable using performance indicators and figures. Also, target effects need to be clearly set apart from target actions and target services in an organization. 'Target effects are concepts of desirable statuses, abilities and behavioural patterns that should be reached after helping someone. Hence they should always be considered in connection with the consumer. Target effects indicate the directionality of the entire enterprise which means they have an orientating function. Target effects are benchmarks for the negotiation of target actions. Target actions are concepts of conditions, interventions and other arrangements that - at least in theory - increase the probability of target effects being reached. ... Target actions should thus have a plausible relation with target effects.' (Heil et al 2001:69) Target actions form the basis of target effects, the pave the way to reaching an effect. On the level where the service is rendered, target services are considered when contemplating the output of an organization (e.g. increasing the number of counselling appointments). Since the quantitative 
form of quality assessment is mostly difficult and time consuming, practitioners increasingly demand an exclusively qualitative presentation of indicators such as satisfaction and wellbeing in order to describe a service. What has to be kept in mind though, is that quality that cannot be measured can hardly be used as a design or control tool either.

By now invitations of tenders during public tendering and award procedures are being used in order to try and define the quality of services. In the course of tendering and award procedures the question arises, whether funding sponsors, suppliers and consumers have the same understanding as far as the services are concerned. The targets are attached to the diverse expectations, needs and wishes of the different stakeholders.

\section{Change of social economy organizations - effects of mana- gerialism?}

As a result of the introduction of management concepts, social economy organizations have changed. Characteristics of the concept of managerialism are summarized in figure 3 (cf. Mayer 2008).

Now the question arises, what effects managerialism has on social economy organizations. So far there are hardly any studies that address this topic. Hereafter the first results of the quantitative study 'Funktionen von NPO' ('NPOs' functions') (NODE-project, 2008) conducted by the Vienna University of Economics and Business' non-profit institute are presented:

- Managerialism (economization) in the social sector is stronger than it is in other NPO areas (participation in public tenders, managing staff with economic training, offer of business-oriented further education for staff, similar income to profit-oriented sector).

- Managarialism promotes service orientation. There is no connection - neither positive nor negative - to partiality and community building.

- Managerialism promotes innovation, not only when it comes to processes but when it comes to products, too (increasing frequency of innovations, product innovation, process innovation). Managerialism also promotes innovation as a category of thinking and decision making.

The first results permit the following cautious conclusion: managerialism - applied within bounds - is useful for social economy organizations. Simultaneously, professionalism of social work needs to be increased. The function of social cohesion and partiality should not be ignored either. In addition to the sometimes varying and even contradictory expectations stakeholders have, staff commitment and voluntary work must be considered as well as the sponsors. 
Figure 3.The concept of managerialism (according to M. Mayer 2008)

\begin{tabular}{|c|c|c|}
\hline & Dimensions & \\
\hline $\begin{array}{c}\text { Professional } \\
\text { dimensions }\end{array}$ & $\begin{array}{c}\text { Social } \\
\text { dimensions }\end{array}$ & $\begin{array}{c}\text { Time } \\
\text { dimensions }\end{array}$ \\
\hline Rationality & $\begin{array}{c}\text { Who takes } \\
\text { decisions? } \\
\text { Who is consulted? }\end{array}$ & $\begin{array}{c}\text { Management as } \\
\text { a continuous } \\
\text { improvement } \\
\text { process }\end{array}$ \\
\hline $\begin{array}{l}\text { - definition } \\
\text { of targets } \\
\text { - assessment of } \\
\text { alternatives } \\
\text { - continuous } \\
\text { evaluation } \\
\text { - continuous } \\
\text { improvement }\end{array}$ & $\begin{array}{c}\text { Roles } \\
\text { (Which roles } \\
\text { are there?) } \\
\text { - managers } \\
\text { - staff } \\
\text { - clients } \\
\text { - counsellors } \\
\text { - competitors }\end{array}$ & $\begin{array}{c}\text { How is time } \\
\text { frame } \\
\text { constructed? } \\
\text { When are } \\
\text { decisions made, } \\
\text { how long does } \\
\text { that take? }\end{array}$ \\
\hline $\begin{array}{c}\text { What's the topic, what } \\
\text { will be decided on? } \\
\text { Application } \\
\text { of management } \\
\text { techniques } \\
(\mathrm{BSC}, \ldots)\end{array}$ & $\begin{array}{c}\text { Individual and } \\
\text { organizational actors }\end{array}$ & $\begin{array}{l}\text { Time as progress } \\
\text { Depreciation } \\
\text { of the past, } \\
\text { emphasis } \\
\text { on the future }\end{array}$ \\
\hline
\end{tabular}

In conclusion it can be said that further studies concerning the application of managerialism and the effects it has on different groups of people, parts of organizations etc. are imperative. For social economy's future development, national and comparative European studies are necessary because results and best practice examples need to be exchanged.

\section{Summary and outlook}

Social economy ensures supply of professional services

Social work is a professional service and social economy provides professional social services with the goal of promoting individual and societal welfare. The range of services offered depends primarily on the welfare state's catalogue of targets and the legal mandate.

$\diamond$ Social economy is an important element in a welfare state 
Social economy is an expression of a state's welfare culture. It developed from a charitable network to a proper economic sector which is mostly publicly financed but receives increasing contributions (fees) from the persons it protects.

$\diamond$ Social economy creates jobs and is a growth sector

Because a further increase in employment levels is to be expected (employment creator), the social economy is increasingly seen as a growth sector and important employer. Already in 2003 more than 11 million people in the EU (25 member states) worked in social economy, i.e. every 16th gainfully employed person which equals nearly $7 \%$ of said group. There are differences between the member states though: the old member states have $7 \%$ of their work force working in the social economy sector while this figure only comes up to $4.2 \%$ in the new member states (Chaves/Monzon 2007, p. 23). At present it's mostly women who work in the sector - many work part time, often under the threshold where social security contributions would become mandatory for the employer - and in future social economy is likely to remain an important source of employment for women.

With more than 2 million enterprises, social economy represents about $10 \%$ of all companies in the EU (Maucher 2010, p. 27). Social economy also constitutes an important part of national economy and has to be regarded as a relevant sector of economy which is of yet not taken into account sufficiently in the grand picture of national economy.

Increasing market orientation and new ways of financing

It can be safely assumed that market orientation in the social services sector will increase further in the future. This might eventually lead to a growth of existing organizations or cooperation between (bigger) social economy organizations in order to be able to compete with profit oriented social enterprises. Also the opening of additional financing sources such as sponsoring and fundraising might gain in significance.

Pointing out the effects (professional and economic)

Due to increasing economic pressure, professionalization is going to increase in two respects. The challenge will be to reconcile professional quality standards and business aspects. For social work professionals this will increasingly mean that effects have to be proven or verified and that services are going to need to be continuously evaluated and developed. In order to further refine the profile of social economy and the social service sector, it is going to be imperative to find a balance between the two functions these organizations have to fulfil. A limitation to the function of producing services and/or the simple demand for cost effectiveness would lead to a loss in self-conception of social economy organizations. 


\section{$\diamond$ Politics' influence}

In principle the further development of both social work and social economy is going to be coined by socio-political decisions made in the individual states and the European Union. (E.g. the respective legislative bodies' financing policy - even within the individual states - will have a strong influence on the further development of social economy.)

$\diamond$ Strengthening the significance of social economy (publicly and in a scientific context)

On the one hand it is important to emphasize and acknowledge social economy's services on a practical and political level; on the other hand a more intense scientific analysis of social economy is imperative. The (statistical) registration of social economy in the individual countries and in the whole of Europe is not always sufficient which means that reliable statements on the actual (national economic) significance cannot really be made. The lack of clearly defined common terminology makes a comparison between European states harder still.

With this in mind the significance of the European Joint Degree Master Course 'Social economy and social work' which was jointly developed by 7 European universities, must be emphasized at this point. This course of studies has a great part in the scientific analysis as well as the further professionalization of social economy organizations in a European context.

\section{References}

- Chaves, R., Monzon, J. L. (2007): Die Sozialwirtschaft in der Europäischen Union, Zusammenfassung des Berichts für den Europäischen Wirtschafts- und Sozialausschuss CIRIEC/IFIG, www.eesc.europa.eu

- Drucker, Peter F. (2001): Managing the Non-Profit Organisation; Practices and principles, Oxford

- Gruber, Christine (2008): Sozial Wirtschaften in der Sozialwirtschaft, in Bassarak, Herbert / Wöhrle Armin (Hg.) (2008): Sozialwirtschaft und Sozialmanagement im deutschsprachigen Raum, Augsburg

- Heil Karolus, Heiner Maja, Feldmann Ursula (Hg.) (2001): Evaluation sozialer Arbeit. Eine Arbeitshilfe mit Beispielen zur Evaluation und Selbstevaluation. Frankfurt am Main: Eigenverlag des Deutschen Vereins für öffentliche und private Fürsorge. 
- Maucher, Matthias (2010): Europa in der Sozialwirtschaft mitdenken ... . Weil die EU verstärkt Politik und Förderinstrumente mitgestaltet, in: Sozial Extra 5/6, S. 27-30.

- Mayer, Michael (2008): Managerialism - der Sieg von Konzepten und Methoden über Personen und Visionen, Vortrag am 6. NPO-Tag, Wien

- Zauner, Alfred (2006): Von der Subvention zum Leistungsvertrag: Neue Koordinations- und Steuerungsformen und ihre Konsequenzen für Nonprofit Organisationen, Eine systemtheoretische Analyse. Bern, Wien. 